\title{
Multilevel elements associated with HIV serosorting for sexual encounters: a scoping literature review
}

\author{
Elementos multinivel asociados a seroclasificación por VIH \\ en encuentros sexuales: revisión de alcance de la literatura
}

Alma Angélica Villa-Rueda (https://orcid.org/0000-0002-2501-2820) ${ }^{1}$
Dora Julia Onofre-Rodríguez (https://orcid.org/0000-0003-1214-9761) ${ }^{2}$
Siobhan Churchill (https://orcid.org/0000-0002-3348-473X) ${ }^{3}$
Fernanda Ramírez-Barajas (https://orcid.org/0000-0002-7237-1447) ${ }^{2}$
Raquel Alicia Benavides-Torres (https://orcid.org/0000-0001-5113-4250) ${ }^{2}$

${ }^{1}$ School of Nursing,

Universidad Autónoma de Baja California. Calle G

S/N Z.C. 21100. Mexicali Baja California México.

donofre64@yahoo.com.mx

${ }^{2}$ School of Nursing,

Universidad Autónoma

de Nuevo León. Dr. José

Eleuterio González \#1500,

Mitras Centro, Z.C. 64460

Monterrey Nuevo León

México.

${ }^{3}$ Department of

Epidemiology and

Biostatistics, University of

Western Ontario. London

ON Canada.

\begin{abstract}
A scoping literature review to identify the multilevel HIV serosorting related elements was developed. Articles from EBSCO, PubMed, PsyNET and Science Direct with serosort ${ }^{*}$ or serosorting at the tittle or abstract, written in English or Spanish were included. No restriction in type of population or design were applied. 239 records were retrieved after duplicates removed, but 181 references were extracted for full-text review. Individual level: HIV knowledge, serostatus, risk perceptions, abilities to disclose and for condom use negotiation, motivations, use of drugs, stigma, attitudes toward condom use, and perceptions/beliefs about the HIV and related treatments, HIV infection rates/testing and behavioral factors. Interpersonal level: social networks, abilities (sexual behavior negotiation, and communication). Community level: stigma, social norms, access to HIV related services. Structural level: political context, HIV related funding and public policies. HIV Serosorting is not solely an interpersonal behavior it involves multilevel elements that must be acknowledged by professionals and stakeholders.

Key words HIV, HIV serosorting, Risk reduction behavior, Sexual behavior
\end{abstract}

Resumen Se desarrolló una revisión de alcance de la literatura para identificar elementos multinivel relacionados a la seroclasificación de VIH. Se incluyeron artículos de EBSCO, PubMed y Science Direct con serosort ${ }^{*}$ o serosorting en título o resumen, escritos en Inglés o Español. No se aplicaron restricciones por tipo de población y diseño. Después de remover duplicados, se recuperaron 239 records, solo 181 referencias se extrajeron para revisión a texto completo. Nivel individual: Conocimiento del VIH, seroestado, percepciones de riesgo, habilidades para develar el seroestado y negociar el condón, motivaciones, uso de drogas, estigma, actitudes sobre uso del condón, y percepciones/creencias acerca del VIH y tratamientos, tasas de infección y tamizaje de VIH, factores conductuales. Nivel interpersonal: redes sociales, habilidades (negociación de la conducta sexual, y comunicación). Nivel comunitario: Estigma, normas sociales, acceso a servicios de VIH. Nivel estructural: contexto político, políticas públicas y financiamiento relacionado al VIH. La seroclasificación de VIH no es solamente una conducta interpersonal, incluye elementos multinivel que deben ser reconocidos por los profesionales de salud y tomadores de decisiones.

Palabras clave VIH, Seroclasificación para el $V I H$, Conducta de reducción de riesgo, Conducta sexual 


\section{Introduction}

Human Immunodeficiency Virus (HIV) is a priority public health issue with implications at the individual, interpersonal, community, and social/structural levels ${ }^{1}$. As of 2016, there were approximately 36.7 million of people living with HIV worldwide ${ }^{2}$. The Joint United Nations Programme on HIV and AIDS (UNAIDS) ${ }^{3}$ classifies several populations as having elevated risk for HIV, including: men who have sex with men (MSM), people who use injectable drugs, people who engage in sex work, and people who identify as transgender. Evidence suggests that because most cases of HIV are transmitted by sexual contact ${ }^{4}$, individuals who are at higher risk of acquiring HIV or people who lives with the HIV (PWLH), have adopted "new" interpersonal sexual behaviors with the goal of mitigating HIV risk $^{5}$. That is the case of serosorting ${ }^{6,7}$.

Serosorting is a concept that was born as a result of the HIV epidemic ${ }^{8}$. Serosorting is acknowledge as a seroadaptative behavior and a risk reduction strategy ${ }^{9}$ that involves a decision-making process to choose how and with whom to have sex in casual partnerships based on HIV serostatus (seroconcordance or serodiscordance) while diminishing the risk to acquire the HIV. Often individuals seek seroconcordant partners to engage in anal or vaginal unprotected sexual intercourse ${ }^{7,10,11}$. Any serosorting-related decisions may be based on perceptions or beliefs about the serostatus of either partner or the results of actual HIV screening tests ${ }^{12,13}$.

Scholars have differentiated two types of HIV serosorting for sexual encounters: serosorting related to couples selection (pure serosorting) and serosorting of condom negotiation (condom serosorting) ${ }^{14-16}$. More recently, serosorting has been defined, as a "form of sexual creativity"17 because the behavior does not necessarily aligns with traditional methods to reduce HIV risk, like condom use. Although in the beginning, serosorting was associated specifically to MSM living with HIV $^{18}$ there is growing evidence that HIV serosorting is being adopted by other populations such as women and heterosexual ${ }^{19}$.

While some studies and syntheses have characterized HIV serosorting as a sexual risk reduction strategy, others have found that serosorting has no effect or increases HIV risk/new infections/reinfection ${ }^{5,15,20-22}$. Identifying and understanding the multilevel elements involved in HIV serosorting process to work, as a sexual risk reduction strategy is crucial in order to reduce
HIV infection/reinfection rates and introduce it in behavioral interventions and strategies.

\section{Current study}

For too long, studies of HIV risk factors were restricted to individual-level behaviors. Recently researchers, health professionals and policy stakeholders have adopted multilevel paths to analyze the HIV epidemic ${ }^{23,24}$. Those models allow identifying and understanding the mechanism involved in a behavior at the micro and macro structural levels, and their mutual and systemic connection $s^{25}$. Identifying, the elements leading to a behavior, from individual motivations to structural barriers, will permit to develop not only intrapersonal risk reduction strategies, but also interventions at the larger societal level ${ }^{25,26}$. Therefore, this paper was guided by the following research questions: Which are the multilevel elements associated with HIV serosorting for sexual encounters?

\section{Method}

A scoping literature review was conducted with the goal of identifying multilevel elements associated with HIV serosorting. Scoping reviews are used to track a concept's attributes in a specific area and the main sources and types of available evidence related to it. By capturing the general evidence, areas of opportunity are identified to be explored or deepened in future studies. The present scoping review followed the guidelines of the Joanna Briggs Institute ${ }^{27}$.

\section{Inclusion and exclusion criteria}

No restrictions in population, country, year or study design were applied. We included articles that identified elements associated with HIV serosorting for sexual encounters in any of the stated levels (e.g. individual, interpersonal), and published until October 2018. Grey literature was excluded at the extraction phase. Articles not related to HIV serosorting for sexual encounters (HCV and share injection) and written in languages other than Spanish and English were excluded from the analysis.

\section{Search strategy}

A first search in PubMed and EBSCO was developed with the aim to identify the words in 
tittle and abstract that would yield the greatest results for HIV serosorting. Words such as negotiated safety, strategic positioning, seroadaptation and seropositioning although related to HIV serosorting did not lead to specific documents for HIV serosorting. Descriptors from $\mathrm{MeSH}$ ("HIV serosorting") and DeCS ("Selección por serología para HIV") were not used in the search strategy, since they yielded only to a small proportion of articles. Since the term of serosorting comes from health, behavioral and, more recently, social sciences, the chosen databases were characterized by containing articles related to these sciences. At the final search articles from PubMed, EBSCO, PsyINFO (Ovid), and Science Direct with serosorting or serosort ${ }^{*}$ in the title or abstract were retrieved.

\section{Data extraction and synthesis}

The extraction and synthesis of documents was conducted between January 2018 and January 2019. Each document was reviewed for inclusion by two independent individuals in two phases (tittle/abstract and full-text). Disagreements were resolved through discussion until consensus was reached. EndNote ${ }^{28}$ citation management software was used to screen the papers for relevance. For the revision of the title and abstract, the reviewers considered that serosorting was reflected as a variable of analysis or as part of the results and/or discussion. Subsequently, a full-text review was conducted. Reviewers retrieved general information of each document (definition, type of research [qualitative, quantitative], data collection country, study population, related concepts and any HIV serosorting related elements acknowledged by the authors at the article's corpus). Ulrichsweb ${ }^{29}$ was used to identify the journal discipline A series of tables were built to organize the information. A guide was developed to integrate uniformly the identified elements by level of analysis.

\section{Results}

In total 377 references were retrieved but only 239 remained after elimination of duplicates. 125 were included in the scoping review after document screening (Figure 1). Figure 2 depicts the retrieved and synthetized information, organized in a schematic model.

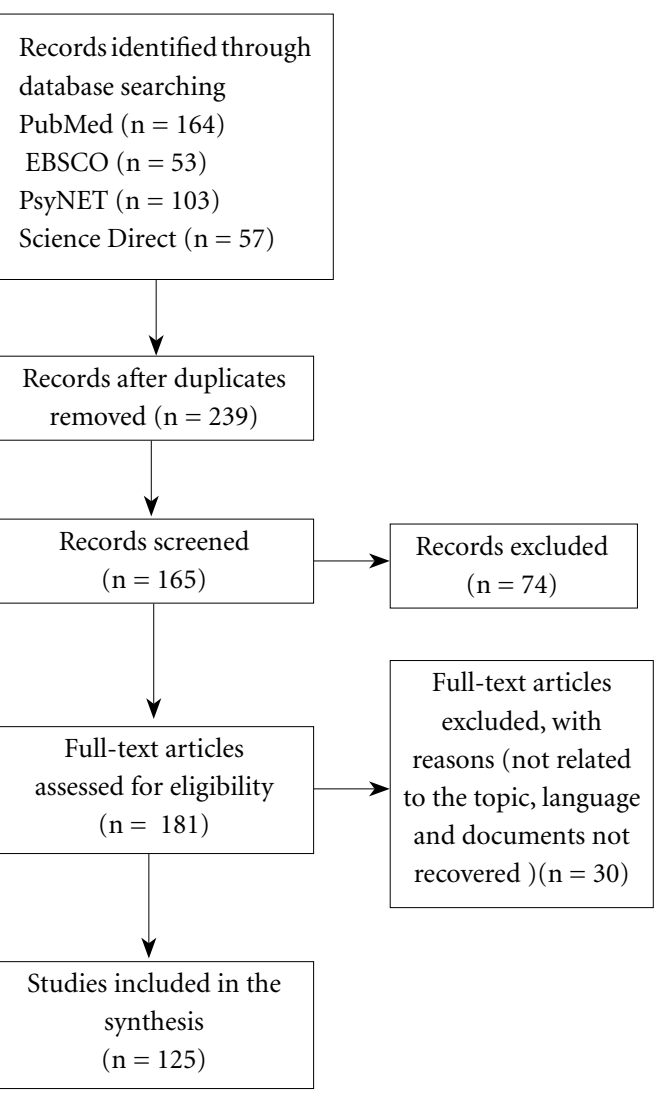

Figure 1. PRISMA diagram flow.

Source: Moher et al. ${ }^{30}$.

\section{Individual level}

HIV serosorting is a sexual behavior that relies on individual's HIV serostatus, for instance individuals must have up-to-date and reliable knowledge of their own serostatus ${ }^{22,31}$. HIV serosorting necessitates individuals have general knowledge of HIV (transmission routes, window period, STIs), for the decision making process ${ }^{10,11}$. HIV related knowledge and individual's awareness of their own serostatus can generate risk perceptions at the individual level. For instance, individuals may perceive themselves as in risk to acquire the HIV and therefore adopt serosorting as a harm reduction strategy. In addition, PWLH may develop responsibility feelings with partners of unknown or seronegative status ${ }^{32,33}$.

HIV serosorting also needs individuals have/ develop abilities/communications skills to dis- 


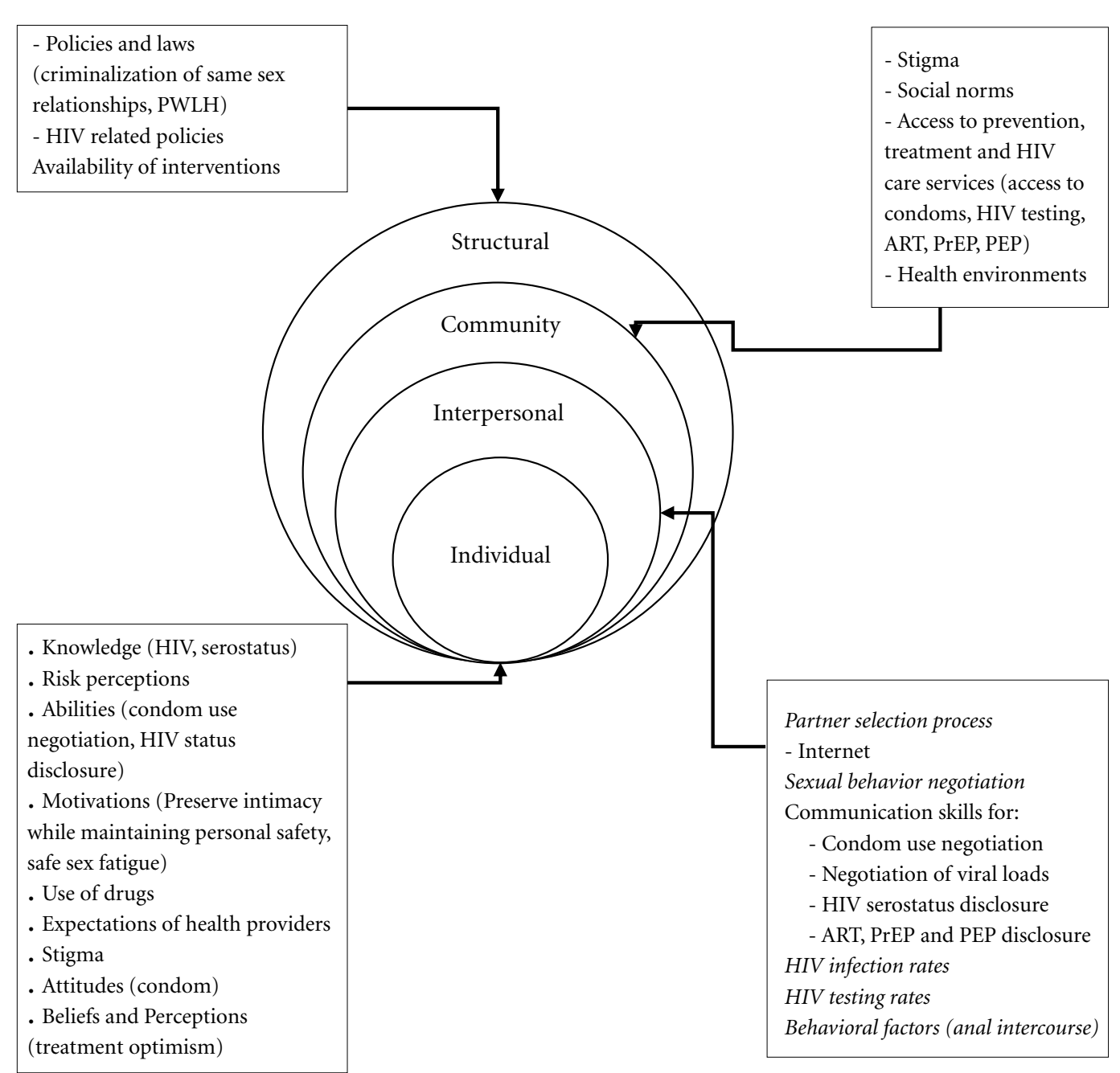

Figure 2. Multilevel elements for HIV Serosorting for sexual encounters identified throughout the scoping review.

Source: Adapted from Kaufman et al..$^{25}$ and Baral et al. ${ }^{1}$.

close their HIV status and to negotiate condom use with potential sexual partners ${ }^{34}$, independently if they already live with the HIV, have negative or unknown serostatus ${ }^{34,35}$. In some cases, the lack of disclosure leads individuals to assume the serostatus of their partners ("seroguessing") ${ }^{36}$. In this case, HIV serosorting can lead to adverse consequences, such as new cases ${ }^{5,15,21,37}$, coinfection, and superinfection/reinfection (acquisition of another strain of HIV) ${ }^{38,39}$.

Individuals may be motivated to practice HIV serosorting to preserve intimacy and personal safety, and avoid safe sex fatigue ${ }^{14,20,40}$. For example, although the main use of serosorting is to reduce the HIV acquisition risk, it was also used to stablish sexual intimacy while maintaining personal safety ${ }^{41,42}$. PWLH often find that having a partner who shares the experience of being HIV positive facilitates emotional, communicative, and sexual intimacy ${ }^{41,42}$.

Safe sex fatigue/condom fatigue may also be a motivation for serosorting. MSM, including gay and bisexual men, have often been the primary focus of HIV prevention strategies. This focus can lead people to experience aversion to traditional safer sex strategies, as well as stigma and exclusion from being told how to have se $\mathrm{x}^{40,43}$.

Individuals beliefs toward the HIV as a mortal or treatable disease can determine the way individuals choose their partners and involve in 
sexual relationships ${ }^{42}$. HIV related beliefs can be connected with beliefs and perceptions (treatment optimism) toward ART, Treatment as Prevention (TasP), PrEP and PEP which may also influence the decision making of individuals who practice HIV serosorting ${ }^{20}$. Nevertheless, expectations of health care services, fear of rejection and even violence or abandonment, use of drugs and attitudes toward condom use are individual barriers related to HIV serosorting ${ }^{11,40,42,44-46}$.

\section{Interpersonal level}

HIV serosorting is characterized as an interpersonal practice because it aims to reduce the risk of acquiring HIV among casual or secondary partners ${ }^{36}$. HIV serosorting involves a partner selection process and sexual behavior negotiation. In both processes, the internet and communication skills play pivotal roles.

Since the Internet became publicly accessible, an increase in the use of web applications for the establishment of sexual encounters among communities has increased. In particular, the Internet can facilitate casual sexual encounters and sometimes even empower people to disclose their HIV status $^{10,47}$. Today, it is not uncommon for dating/ hookup platforms to collect data on HIV status, testing and treatment which can be displayed to other users and enable HIV serosorting ${ }^{31}$. Since the internet provides a semi-anonymous environment, individuals can more safely disclose their HIV status and/or simply seek profiles of seroconcordant partners ${ }^{48}$. However, HIV disclosure on dating/hookup apps has also raised concerns of discrimination against $\mathrm{PWLHV}^{36,49}$.

As the partner selection and the sexual negotiation processes are based on the exchange of information, some degree of communication between partners is required. Even if there is not a face-to-face encounter. Communication skills are used to disclose one's HIV serostatus ${ }^{32,34}$. Sexual behavior negotiation includes condom negotiation between both partners. If partners are serodiscordant, condom use often is necessary in order to mitigate HIV risk. Among partners with the same serostatus, partners may tend to refuse condom use. In the case of individuals who report an HIV-negative serostatus based on HIV testing, it is necessary to consider the window period. In the context of couples where both partners are living with the HIV, viral loads and treatment usage must be considerate ${ }^{39,50}$.

In some cases, individuals taking ART may move on to negotiate the viral load or mixing
HIV serosorting with another seroadaptative behavior such as seropositioning in order to avoid condom use ${ }^{16,20,51}$. Also, individuals may advance to enhanced practices of serosorting which mix biomedical treatments and behavioral methods such as bio sorting and biomed sorting and biomed matching ${ }^{31}$.

Serosorting also relies on other interpersonal factors such as the HIV infection rates and behavioral practices within the sexual networks. As HIV serosorting is sexual practice mostly practice it among key populations, HIV infection rates are important to weight the risk within the members of the community as well as the HIV screening frequency ${ }^{52}$. Also, if HIV rates in a specific geographic area are high, the likelihood of people knowing their HIV status is also high, which is essential for serosorting. The same happens with sexual behaviors. Anal sex is the main transmission route of HIV in communities such as MSM, gay men and bisexual ${ }^{20}$.

\section{Community level}

Community elements related to HIV serosorting are stigma, social norms, access to HIV testing and prevention, treatment and health care services, HIV infection rates and behavioral factors within the community (e.g. among MSM).

Stigma is structured by social/structural elements which penetrates and have consequences to the individual level ${ }^{34}$. Populations who most frequently practice serosorting as an HIV preventive/harm reduction behavior such as MSM, gay and bisexual men, face multiple forms of stigma based on their sexual orientation, which may be compounded by discrimination related to living with the HIV ${ }^{42}$.

PWLH may opt for HIV serosorting as a strategy to have casual sex while diminishing HIV-related stigma and enhancing the chances to have pleasurable sex. Some individuals may feel that because their HIV serostatus the range of possible sexual partners is reduced. PWLH can potentially be rejected by sero-discordant partners and some other may experience an "anticipated rejection" or an "actual anticipated rejection". Some scholars has name this phenomenon as serodivision, where individuals are isolated according to their HIV status ${ }^{41,42}$.

Access to HIV testing is crucial for HIV serosorting to work as a risk reduction strategy ${ }^{34}$. Health providers have a central role for HIV testing. However, stigma and discrimination at health contexts and by health providers become a barrier 
for individuals to access to HIV testing and preventive, treatment and health care services ${ }^{44}$.

\section{Social/structural level}

Among the social/structural elements linked to HIV serosorting are availability of policies that protect, recognize and/or penalize same-sex relationships, as well as criminalization of $\mathrm{PWLH}^{34}$. For instance, as individuals perceive a friendlier context for same-sex relationships and protection and/or political recognition, there may be less risk of them entering into casual relationships and therefore having risky sex ${ }^{53,54}$.

On the other hand, given that some populations are rejecting condom use public health policy is adopting HIV serosorting as an option to mitigate the HIV risk among those communities ${ }^{7}$. Introducing HIV serosorting as a harm reduction practice in public health policy, strategies and interventions, and individual's access also depend on the availability of funding. Financing of HIV related strategies rely upon existing public policy recognizing the HIV epidemic. HIV related funding may also determinate the existence and access to HIV related services, condoms, testing and HIV treatment. Policies promoting HIV testing have a pivotal role for HIV serosorting ${ }^{34}$.

Figure 3 depicts the areas/disciplines of the journals, populations and main settings were serosorting has been referenced and applied. Most articles belong to the medical sciences, and psychology. 117 articles were specifically developed among MSM or in combination with gay and bisexual men. The rest of the documents included women, men (heterosexuals) and trans people. The majority of the studies were developed in the United States of America (USA), Australia and Canada.

\section{Discussion}

The preceding scoping literature review presents all known key related multilevel factors of HIV serosorting. Results show that the disproportionate burden of HIV faced by certain populations, such as MSM, gay/bisexual men, has led to the evolution of novel sexual behaviors with the goal of reducing HIV acquisition/transmission risk ${ }^{5,6}$. However, there is growing evidence that other populations such as transgender, women and heterosexual individuals are putting into practice $e^{15,34,55}$.
These seroadaptative practices include HIV serosorting, which has been further influenced by HIV treatment, as well as the internet as a means of communication and liaison for sexual networks ${ }^{20,56,57}$. Rowniak ${ }^{6}$ explains that the public's perception of HIV as a treatable illness has been associated with a reduction in safer sex practices, and with the uptake of novel seroadaptative behaviors.

While serosorting and other seroadaptive behaviours are also by no means perfect risk-reduction strategies, they allow PWLH to subvert society's assertion that the responsibility for having safe sex lies only with HIV positive partners ${ }^{58}$. Serosorting can empower people with HIV to have sex that is pleasurable, safe, and intimate. Nevertheless, HIV serosorting also may be causing a serodivision phenomenon within key populations, which may be linked to processes of social construction of HIV, stigmatization and discrimination ${ }^{34,42}$.

In geographically nested communities with high rates of HIV screening, serosorting has been found to reduce new HIV cases $^{18}$. In settings with low rates of HIV screening, researchers have found that serosorting increases the HIV risk ${ }^{31}$. For example, Wilson et al. ${ }^{58}$ developed a mathematical model to estimate serosorting risk for HIV, considering the rates of PWLH but are undiagnosed. Authors used statistical estimations from previous studies on the percentage of undiagnosed PWLHV from five locations (Sydney, USA, USA, London, Sub-Saharan Africa). The relative risk for serosorting in those locations with less people undiagnosed had better chances for serosorting to work as a HIV risk reduction strategy. If we consider that HIV serosorting relies on individuals know their actual HIV serostatus, is not surprising that higher rates of HIV screening, may reflect higher rates of individuals knowing their HIV serostatus, and therefore HIV serosorting may have more probabilities to work as a risk reduction strategy. At present, there are different ways for individuals to get tested for HIV, in addition to HIV specific clinics and services, such as "mobile testing units", and more recently through test kits that are sent to the individual's homes $^{42}$. However, it is important to consider that not all countries offer this type of testing options, provide individuals with PrEP PEP, and/or even to PWLH with treatment ${ }^{59,60}$.

Currently, political and structural changes are taking place around the world, which may being repercuting the HIV epidemic. The persistence of policies that make invisible the ex- 


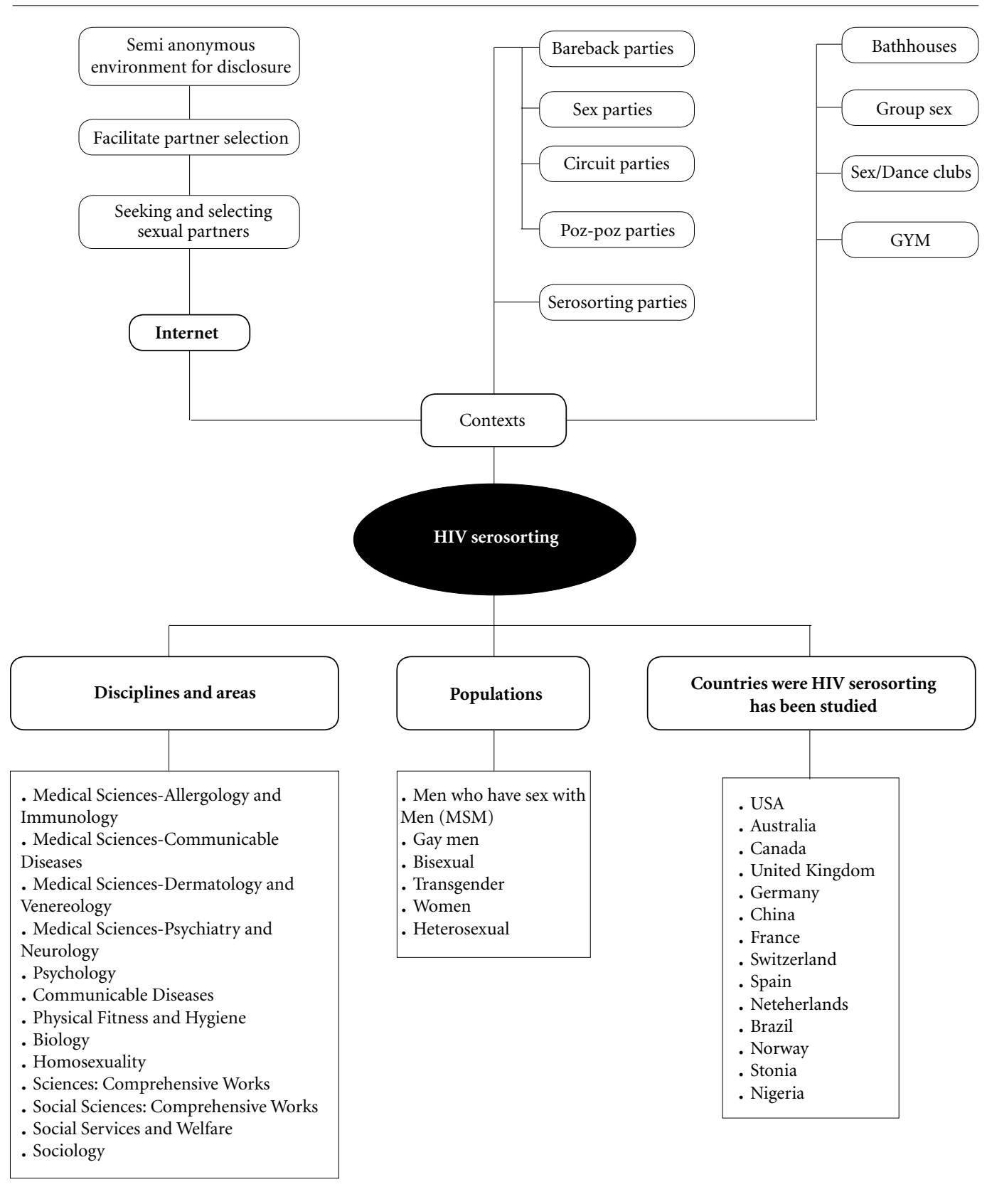

Figure 3. Most common HIV serosorting contexts, journal disciplines and populations identified through the scoping review.

Source: Authors own elaboration.

istence and rights of LGBTIQ+ populations or which criminalized them, continue legitimizing stigma and discrimination against those populations, and may be impacting their access to HIV health services ${ }^{61}$. By 2019, 71 locations were detected around the world that maintained penalties related to same sex acts $^{62}$. It has been previ- ously documented that discrimination and acts of violence based on sexual orientation and other sexual identities are related to increased odds of living with $\mathrm{HIV}^{60}$.

Additionally, across the world it is common for government policies to diminish the sexual autonomy of PWLH by enforcing legal require- 
ments that they disclose their HIV status prior to having sex, as is happening in Canada and Mexico $^{63}$. These policies are often compounded by pervasive (though well-intentioned) targeted messaging encouraging affected communities to get tested and practice safer sex. However, in everyday life, HIV disclosure is not always safe, HIV testing is not always accessible, and safer sex is not always easy. Anti-related sexual diversity initiatives may result in criminalization of key populations, reduction of funding for HIV prevention, detection and treatment, and with the increase in discrimination and stigma within and out communities ${ }^{63}$.

Political strategies such as the 90-90-90 targets may be having positive impacts in the HIV epidemic $^{64}$ especially for individuals who are using harm reduction practices such as HIV serosorting and live in contexts that are embracing policies to end the HIV epidemic ${ }^{60}$. This political strategy aims to $90 \%$ of individuals living with the HIV know their status, $90 \%$ is under treatment and $90 \%$ are virally suppressed. Thus, individuals practicing HIV serosorting and living in contexts that are embracing policies to end the HIV epidemic, may have more access to HIV screening and treatment, and having an HIV upto-date knowledge of their serostatus.

Additionally, the role health providers are playing at the community/institutional levels, and health providers attitudes toward HIV, PWLH and key populations needs are decisive for HIV testing as basis for HIV serosorting ${ }^{64,65}$. The "Zero discrimination in health care settings" strategy acknowledge and deploys an agenda to address the discrimination faced by key populations and PWLH in health care settings. Discrimination in health services can reduces the likelihood that individuals access to HIV information, prevention, HIV testing, and treatment. Discrimination in health care settings may depend of public policy for providing health providers with HIV specific training ${ }^{66}$.

For health providers and professionals working in the HIV epidemic, having a clear understanding of HIV serosorting and its related factors is imperative to educate key populations at risk, to understand the epidemic and introduce them in HIV related strategies ${ }^{26}$. Furthermore, the human being is compounded of multiple dimensions (i.e. spiritual, social) so health professionals must also acknowledge that clinical and epidemiological outcomes are not the only consequences or even motivations of serosorting ${ }^{7,40}$. The World Health Organization ${ }^{66}$ states that safe and pleasurable sex is an important component of sexual health and multidimensional welfare. Understanding that sexual decision making as a process that should be safe, consensual, and communicative is the first step to understanding the motivations for HIV serosorting ${ }^{55}$.

HIV serosorting is an evolving behavior connected with the availability of new treatments, technologies and methods of prevention and therefore needs constant scrutiny. Grov et al..$^{31}$ explains that aftermath the use of ART and Pre-Exposure Prophylaxis (PrEP), individuals have started to mix biomedical treatment and behavioral practices. It is important to acknowledge that although HIV serosorting decreases the risk of acquiring HIV when compared to unprotected intercourse, even under the best conditions (eg availability of HIV-related services), HIV serosorting has been associated with an increase in sexually transmitted infections $s^{5,18}$.

Health providers and stakeholders cannot obligate individuals to stop practicing HIV serosorting but they can provide them with accurate and reliable information for the decision making process.

\section{Final considerations}

In order to determine the chances for serosorting to reduce or increase HIV acquisition risk, it is necessary to consider all of the multilevel elements necessary to make HIV serosorting effective as a harm reduction strategy and all those characteristics, which introduce risk. Considering that the present review showed that the practice of HIV serosorting as a risk reduction strategy has expanded to other countries outside the USA, where it seems to have originated ${ }^{18}$ it would be favorable to develop previous diagnosis, analysis and measurement of the availability of local individual and interpersonal elements, a given society's norms and attitudes, as well as social and structural determinants of health, including punitive HIV non-disclosure policies, public HIV literacy, same sex acts, and the availability of HIV testing, treatment and condoms.

Interventions should include information of consequences related to HIV serosorting, treatment benefits (undetectable viral loads) and strategies for treatment and viral load disclosure and negotiation. Interventions need to include health providers to generate sensitive and informed environments for PWLH and key populations. Analysis of partner's selection processes 
through internet apps for casual encounters can help to understand serodivision phenomenon. Qualitative studies can help to further deepen into individuals/communities intentions, motivations, beliefs and perceptions related to HIV and HIV serosorting.

\section{Collaborations}

AA Villa-Rueda worked on the conception, design, study selection process, data extraction, data synthesis and analysis and manuscript drafting. DJ Onofre-Rodríguez worked on the search strategy design and manuscript drafting. S Churchill worked on the manuscript drafting. F Ramírez-Barajas worked on the study selection process, data extraction, data synthesis and analysis. RA Benavides-Torres worked on the search, strategy design and manuscript drafting. All authors read and approved the final manuscript. 


\section{References}

1. Baral S, Logie CH, Grosso A, Wirtz AL, Beyrer C. Modified social ecological model: a tool to guide the assessment of the risks and risk contexts of HIV epidemics. BMC Public Health 2013; 13(1):482.

2. World Health Organization (WHO). Sexually transmitted infections (STIs) [Internet]. 2016 [cited 2018 Nov 26]. Available from: http://www.who.int/newsroom/fact-sheets/detail/sexually-transmitted-infections-(stis).

3. The Joint United Nations Programme on HIV and AIDS (UNAIDS). On the fast-track to end AIDS. Geneva: UNAIDS; 2016.

4. Centers for Disease Control and Prevention (CDC). Sexual risk behaviors: HIV, STD, \& teen pregnancy prevention [Internet]. 2018 [cited 2018 Nov 28]. Available from: https://www.cdc.gov/healthyyouth/sexualbehaviors/index.htm.

5. Purcell DW, Higa D, Mizuno Y, Lyles C. Quantifying the harms and benefits from serosorting among HIV-negative gay and bisexual men: a systematic review and meta-analysis. AIDS Behav 2017; 21(10):2835-2843.

6. Rowniak S. Safe Sex fatigue, treatment optimism, and serosorting: new challenges to HIV prevention among men who have sex with men. J Assoc Nurses AIDS Care 2009; 20(1):31-38.

7. Eaton LA, Kalichman SC, Cain DN, Cherry C, Stearns HL, Amaral CM, Flanagan JA, Pope HL. Serosorting sexual partners and risk for HIV among men who have sex with men. Am J Prev Med 2007; 33(6):479485.

8. Elford J. Changing patterns of sexual behaviour in the era of highly active antiretroviral therapy. Curr Opin Infect Dis 2006; 19(1):26-32.

9. Halkitis PN, Moeller RW, Pollock JA. Sexual practices of gay, bisexual, and other nonidentified MSM attending New York City gyms: patterns of serosorting, strategic positioning, and context selection. J Sex Res 2008; 45(3):253-261.

10. Truong HHM, Kellogg T, Klausner JD, Katz MH, Dilley J, Knapper K, Chen S, Prabhu R, Grant RM, Louie $\mathrm{B}, \mathrm{McF}$ arland W. Increases in sexually transmitted infections and sexual risk behaviour without a concurrent increase in HIV incidence among men who have sex with men in San Francisco: a suggestion of HIV serosorting? Sex Transm Infect 2006; 82(6):461-466.

11. Xia Q, Molitor F, Osmond DH, Tholandi M, Pollack LM, Ruiz JD, Catania JA. Knowledge of sexual partner's HIV serostatus and serosorting practices in a California population-based sample of men who have sex with men. AIDS 2006; 20(16):2081-2089.

12. Marcus U, Voss L, Kollan C, Hamouda O. HIV incidence increasing in MSM in Germany: factors influencing infection dynamics. Euro Surveill 2006; 11(9):157-160.

13. Eaton LA, Kalichman SC, O'Connell DA, Karchner WD. A strategy for selecting sexual partners believed to pose little/no risks for HIV: serosorting and its implications for HIV transmission. AIDS Care 2009; 21(10):1279-1288.
14. Snowden JM, Raymond HF, McFarland W. Seroadaptive behaviours among men who have sex with men in San Francisco: the situation in 2008. Sex Transm Infect 2011; 87(2):162-164.

15. Kennedy CE, Bernard LJ, Muessig KE, Konda KA, Akl EA, Lo Y-R, Gerbase A, O’Reilly KR. Serosorting and HIV/STI infection among HIV-negative MSM and transgender people: a Systematic review and meta-analysis to inform WHO guidelines. J Sex Transm Dis 2013; 2013:583627.

16. Pines HA, Gorbach PM, Weiss RE, Shoptaw S, Landovitz RJ, Javanbakht M, Ostrow DG, Stall RD, Plankey M. Sexual risk trajectories among MSM in the United States: implications for pre-exposure prophylaxis delivery. J Acquir Immune Defic Syndr 2014; 65(5):579586.

17. White JM, Hidalgo AP, Bazzi AR, Reisner SL, Mimiaga MJ. Indicators of HIV-risk resilience among men who have sex with men: a content analysis of online profiles. Sex Health 2016; 13(5):436.

18. Centers for Disease Control and Prevention (CDC). San Francisco serosorting may explain odd HIV data: STDs have risen, butnot new HIV infections; Internet sex apparently not issue. AIDS Alert 2004; 19(5):55.

19. Liu C, Hu H, Goparaju L, Plankey M, Bacchetti P, Weber K, Correa N, Nowicki M, Wilson TE. Sexual serosorting among women with or at risk of HIV infection. AIDS Behav 2011; 15(1):9-15.

20. Card KG, Lachowsky NJ, Cui Z, Carter A, Armstrong H, Shurgold S, Moore D, Hogg RS, Roth EA. A latent class analysis of seroadaptation among gay and bisexual men. Arch Sex Behav 2018; 47(1):95-106.

21. Maulsby C, Millett G, Lindsey K, Kelley R, Johnson K, Montoya D, Holtgrave D. HIV among Black men who have sex with men (MSM) in the United States: A review of the literature. AIDS Behav 2014; 18(1):10-25.

22. Torres RMC, Cruz MM, Périssé ARS, Pires DRF. High HIV infection prevalence in a group of men who have sex with men. Braz J Infect Dis 2017; 21(6):596-605.

23. Baral S, Poteat T, Strömdahl S, Wirtz AL, Guadamuz TE, Beyrer C. Worldwide burden of HIV in transgender women: a systematic review and meta-analysis. Lancet Infect Dis 2013; 13(3):214-222.

24. DiClemente RJ, Salazar LF, Crosby RA, Rosenthal SL. Prevention and control of sexually transmitted infections among adolescents: the importance of a socio-ecological perspective - a commentary. Public Health 2005; 119(9):825-836.

25. Kaufman MR, Cornish F, Zimmerman RS, Johnson BT. Health behavior change models for HIV prevention and AIDS care. J Acquir Immune Defic Syndr 2014; 66 (Supl. 3):S250-S258.

26. Blackwell CW. Serosorting sexual partners by gay and bisexual men to prevent HIV infection: implications for public health clinicians. Public Health Nurs 2015; 32(5):555-564.

27. Peters MDJ, Godfrey CM, Khalil H, McInerney P, Parker D, Soares CB. Guidance for conducting systematic scoping reviews. Int J Evid Based Healthc 2015; 13(3):141-146. 
28. Clarivate Analytics. EndNote Web [software]. 2018 [cited 2019 Jan 3]. Available from: https://access.clarivate.com/login?app=endnote.

29. ProQuest LLC. Ulrichs Web Global Serials Directory [Internet]. 2019 [cited 2019 May 15]. Available from: http://ulrichsweb.serialssolutions.com/login.

30. Moher D, Liberati A, Tetzlaff J, Altman DG, The PRISMA Group. Preferred Reporting Items for Systematic Reviews and Meta-Analyses: The PRISMA Statement. PLoS Med 2009; 6(7):e1000097.

31. Grov C, Jonathan Rendina H, Patel VV, Kelvin E, Anastos K, Parsons JT. Prevalence of and factors associated with the use of HIV serosorting and other biomedical prevention strategies among men who have sex with men in a US Nationwide survey. AIDS Behav 2018; 22(8):2743-2755.

32. Parsons JT, Schrimshaw EW, Wolitski RJ, Halkitis PN, Purcell DW, Hoff CC, Gómez CA. Sexual harm reduction practices of HIV-seropositive gay and bisexual men: serosorting, strategic positioning, and withdrawal before ejaculation. AIDS 2005;19 (Supl. 1):S13-S25.

33. Marcus U, Schink SB, Sherriff N, Jones A-M, Gios L, Folch C, Berglund T, Nöstlinger C, Niedźwiedzka-Stadnik M, Dias SF, Gama AF, Naseva E, Alexiev I, Staneková D, Toskin I, Pitigoi D, Rafila A, Klavs I, Mirandola M, Sialon II Network. HIV serostatus knowledge and serostatus disclosure with the most recent anal intercourse partner in a European MSM sample recruited in 13 cities: results from the Sialon-II study. BMC Infect Dis 2017; 17(1):730.

34. Tang W, Liu C, Cao B, Pan SW, Zhang Y, Ong J, Fu H, Ma B, Fu R, Yang B, Ma W, Wei C, Tucker JD. Receiving HIV serostatus disclosure from partners before sex: results from an online survey of Chinese men who have sex with men. AIDS Behav 2018; 22(12):3826-3835.

35. Haas SM, Perazzo JD, Ruffino AH, Ancona RM, Lyons M. The Know ${ }^{\star}$ Now Project: facilitated serosorting in HIV-status sexual partner communication. AIDS Educ Prev 2017; 29(5):432-442.

36. Prestage G, Bavinton B, Callander D, Philpot SP, Zablotska I, Kolstee J, Keen P, Bradley J, Jin F. Australian gay and bisexual men's online preferences about sex with HIV-positive partners. Sex Health 2017; 14(3):221.

37. Butler DM, Smith DM. Serosorting can potentially increase HIV transmissions. AIDS 2007; 21(9):12181220.

38. Matser A, Heijman T, Geskus R, de Vries H, Kretzschmar M, Speksnijder A, Xiridou M, Fennema H, Schim van der Loeff M. Perceived HIV status is a key determinant of unprotected anal intercourse within partnerships of men who have sex with men in Amsterdam. AIDS Behav 2014; 18(12):2442-2456.

39. Stirratt MJ, Marks G, O'Daniels C, Cachay ER, Sullivan M, Mugavero MJ, Dhanireddy S, Rodriguez AE, Giordano TP. Characterising HIV transmission risk among US patients with HIV in care: a cross-sectional study of sexual risk behaviour among individuals with viral load above 1500 copies/mL. Sex Transm Infect 2017; 94(3):206-211.
40. Pantalone DW, Valentine SE, Jackson MA, Andrasik MP, Simoni JM. Partner abuse among HIV-positive sexual minority men: "that was all I deserved...”. Qual Health Res 2017; 27(11):1713-1724.

41. Koester KA, Erguera XA, Kang Dufour M-S, Udoh I, Burack JH, Grant RM, Myers J. "Losing the phobia:" understanding how HIV pre-exposure prophylaxis facilitates bridging the serodivide among men who have sex with men. Front Public Health 2018; 6:250.

42. van den Boom W, Konings R, Davidovich U, Sandfort T, Prins M, Stolte IG. Is serosorting effective in reducing the risk of HIV infection among men who have sex with men with casual sex partners? J Acquir Immune Defic Syndr 2014; 65(3):375-379.

43. Golden MR, Wood RW, Buskin SE, Fleming M, Harrington RD. Ongoing risk behavior among persons with HIV in medical care. AIDS Behav 2007; 11(5):726-735.

44. Jacobs RJ, Kane MN, Sklar EM. Sexual communication and seroadaptation practices in HIV-negative midlife and older men who have sex with men. J Soc Serv Res 2017; 43(2):193-204.

45. Grewal R, Allen VG, Gardner S, Moravan V, Tan DHS, Raboud J, Bayoumi AM, Kaul R, Mazzulli T, McGee F, Rourke SB, Burchell AN. Serosorting and recreational drug use are risk factors for diagnosis of genital infection with chlamydia and gonorrhoea among HIV-positive men who have sex with men: results from a clinical cohort in Ontario, Canada. Sex Transm Infect 2017; 93(1):71-75.

46. Cruess DG, Burnham KE, Finitsis DJ, Goshe BM, Strainge L, Kalichman M, Gebler T, Cherry C, Kalichman SC. A randomized clinical trial of a brief internet-based group intervention to reduce sexual transmission risk behavior among HIV-positive gay and bisexual men. Ann Behav Med 2018; 52(2):116-129.

47. Berry M, Raymond HF, Kellogg T, McFarland W. The Internet, HIV serosorting and transmission risk among men who have sex with men, San Francisco. AIDS 2008; 22(6):787-789.

48. Golub SA, Lelutiu-Weinberger C, Surace A. Experimental investigation of implicit HIV and preexposure prophylaxis stigma: evidence for ancillary benefits of preexposure prophylaxis use. J Acquir Immune Defic Syndr 2018; 77(3):264-271.

49. Katz DA, Golden MR, Stekler JD. Use of a home-use test to diagnose HIV infection in a sex partner: a case report. BMC Res Notes 2012; 5(1):440.

50. Dangerfield DT, Carmack CC, Gilreath TD, Duncan DT. Latent classes of sexual positioning practices and sexual risk among men who have sex with men in Paris, France. AIDS Behav 2018; 22(12):4001-4008.

51. Grov C, Jonathan Rendina H, Patel VV, Kelvin E, Anastos K, Parsons JT. Prevalence of and factors associated with the use of HIV serosorting and other biomedical prevention strategies among men who have sex with men in a US Nationwide survey. AIDS Behav 2018; 22(8):2743-2755.

52. Zablotska IB, Imrie J, Prestage G, Crawford J, Rawstorne P, Grulich A, Jin F, Kippax S. Gay men's current practice of HIV seroconcordant unprotected anal intercourse: Serosorting or seroguessing? AIDS Care 2009; 21(4):501-510. 
53. Fernández-Dávila P, Folch C, Lorca KZ, Casabona J. Silence and assumptions: narratives on the disclosure of HIV status to casual sexual partners and serosorting in a group of gay men in Barcelona. Int J Sex Heal 2011; 23(2):139-155.

54. Eaton LA, Kalichman SC, Kalichman MO, Driffin DD, Baldwin R, Zohren L, Conway-Washington, C. Randomised controlled trial of a sexual risk reduction intervention for STI prevention among men who have sex with men in the USA. Sex Transm Infect 2018; 94(1):40-45.

55. Holt M. Gay men's HIV risk reduction practices: the influence of epistemic communities in HIV social and behavioral research. AIDS Educ Prev 2014; 26(3):214223.

56. Iacob SA, Iacob DG, Jugulete G. Improving the adherence to antiretroviral therapy, a difficult but essential task for a successful HIV treatment-clinical points of view and practical considerations. Front Pharmacol 2017; 8:831.

57. Parsons JT, Severino J, Nanin J, Punzalan JC, von Sternberg K, Missildine W, Frost D. Positive, negative, unknown: assumptions of HIV status among HIV-positive men who have sex with men. AIDS Educ Prev 2006; 18(2):139-149.

58. Wilson DP, Regan DG, Heymer K-J, Jin F, Prestage GP, Grulich AE. Serosorting may increase the risk of HIV acquisition among men who have sex with men. Sex Transm Dis 2010; 37(1):13-17.

59. The Joint United Nations Programme on HIV and AIDS (UNAIDS). Miles to go-closing gaps, breaking barriers, righting injustices. Geneva: UNAIDS; 2018.

60. The Joint United Nations Programme on HIV and AIDS (UNAIDS). Miles to go: the response to HIV in Latin America. Geneva: UNAIDS; 2018.

61. International Lesbian, Gay, Bisexual Trans and Intersex Association (ILGA). Sexual orientation laws in the world. From criminalization of consensual samesex sexual acts between adults to protection against discrimination based on sexual orientation [Internet]. 2019 [cited 2019 Apr 15]. Available from: https://ilga. org/downloads/ILGA_Sexual_Orientation_Laws_ Map_2019.pdf.
62. International AIDS Society. Condemning Tanzania's anti-gay initiatives - News [Internet]. 2018 [cited 2019 Jan 2]. Available from: https://www.iasociety.org/ The-latest/News/ArticleID/209/Condemning-Tanzania's-anti-gay-initiatives.

63. The Joint United Nations Programme on HIV and AIDS (UNAIDS). Live positively: Know your HIV status. Geneva: UNAIDS;2018.

64. O'Byrne P, Phillips JC, Kitson C, Bryan A. HIV status and sexual behaviour among gay men in Ottawa: considerations for public health. BMJ Open 2014; 4(9):e005065.

65. The Joint United Nations Programme on HIV and AIDS (UNAIDS). Zero discrimination in health care settings. Geneva: UNAIDS; 2017.

66. World Health Organization (WHO). Sexual Health [Internet]. 2016 [cited 2018 Nov 18]. Available from: https://www.who.int/topics/sexual_health/en/.

Article submitted 21/01/2019

Approved 05/08/2019

Final version submitted 07/08/2019

Chief Editors: Romeu Gomes, Antônio Augusto Moura da Silva 